\title{
A high-fat challenge increases airway inflammation and impairs bronchodilator recovery in asthma
}

\author{
Lisa G. Wood, PhD, ${ }^{a}$ Manohar L. Garg, PhD, ${ }^{\mathbf{b}}$ and Peter G. Gibson, MBBS ${ }^{\mathbf{a}, \mathbf{c}} \quad$ Newcastle, Australia
}

Background: Dietary fat activates systemic innate immune responses, but the effect on airway responses is unknown. Objective: To examine effects of a high-fat versus low-fat meal on systemic and airway inflammation in asthma.

Methods: Nonobese subjects with asthma were randomized to consume a high-fat $(n=19 ; 48 \%[49 \mathrm{~g}]$ fat $)$ or low-fat $(n=18$; $15 \%$ [ $3 \mathrm{~g}$ ] fat) meal. Fourteen obese patients with asthma and 21 healthy controls also consumed a high-fat meal. Another group of patients with asthma consumed a high-trans $(\mathrm{n}=5 ; 5.2 \mathrm{~g}$ trans fat) or nontrans $(\mathrm{n}=5,<0.3 \mathrm{~g}$ trans fat) fatty acid meal. Lung function was measured at baseline (prebronchodilator) and 2,3, and 4 hours after bronchodilator. Airway inflammation was assessed by using induced sputum cell counts and Toll-like receptor 4 mRNA expression by real-time PCR. Systemic inflammation was measured by ELISA quantification of plasma TNF- $\alpha$, high-sensitivity C-reactive protein, and IL-6 concentrations.

Results: In patients with asthma, at 4 hours postmeal, increases in sputum \% neutrophils and Toll-like receptor 4 mRNA expression were higher and increases in $\mathrm{FEV}_{1} /$ forced vital capacity (FVC) were lower in the high-fat versus low-fat groups. Changes in plasma fatty acids correlated with changes in sputum \% neutrophils and were negatively associated with changes in \% $\mathrm{FEV}_{1}$, \% FVC, and $\mathrm{FEV}_{1} / \mathrm{FVC}$. After the hightrans fatty acid meal, sputum \% neutrophils were significantly higher than after the nontrans meal.

Conclusion: A high-fat meal augments neutrophilic airway inflammation, with the effect dependent on the type of fat consumed. A high-fat meal also suppresses bronchodilator recovery in asthma. Modifying dietary fat intake may be useful in asthma. ( $J$ Allergy Clin Immunol 2011;127:1133-40.)

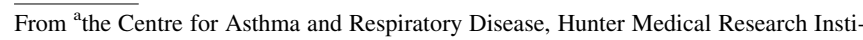
tute, and ${ }^{b}$ the Nutraceuticals Research Group, School of Biomedical Sciences and Pharmacy, University of Newcastle; and the Department of Respiratory and Sleep Medicine, John Hunter Hospital.

Supported by a National Health and Medical Research Council of Australia Project Grant and a Hunter Medical Research Institute project grant sponsored by the Piggott family.

Disclosure of potential conflict of interest: L. G. Wood has received honoraria from GlaxoSmithKline and has received research support from the National Health and Medical Research Council. M. L. Garg declares no conflicts of interest. P. G. Gibson has received honoraria from GlaxoSmithKline and Boehringer Ingelheim and has received research support from the National Health and Medical Research Council.

Received for publication September 3, 2010; revised January 13, 2011; accepted for publication January 17, 2011.

Available online March 5, 2011.

Reprint requests: Lisa G. Wood, PhD, Respiratory Medicine, Level 3, Hunter Medical Research Institute, John Hunter Hospital, Newcastle, NSW, Australia. E-mail: lisa. wood@newcastle.edu.au.

0091-6749/\$36.00

(C) 2011 American Academy of Allergy, Asthma \& Immunology

doi:10.1016/j.jaci.2011.01.036
}

Key words: Dietary fat, fatty acids, neutrophils, Toll-like receptor 4, innate immunity, asthma, bronchodilator recovery, airway inflammation

Discuss this article on the JACI Journal Club blog: www. jaci-online.blogspot.com.

Fatty acids are an essential dietary component, providing the key energy source in vivo. However, metabolism of a high-fat meal results in transient production of proinflammatory mediators, with damaging effects occurring when fats are consumed in excess. Fatty acids initiate innate immune responses via mechanisms such as Toll-like receptor (TLR) activation. Recent evidence demonstrates that TLR4 is activated by dietary fatty acids such as lauric, palmitic, and oleic acids. ${ }^{1-3}$ In vivo experiments have demonstrated that within 1 hour of consumption of a high-fat meal, innate immune responses are stimulated, with increased TLR2, TLR $4,{ }^{4}$ and nuclear factor- $\kappa \mathrm{B}(\mathrm{NF}-\kappa \mathrm{B})$ activity ${ }^{5,6}$ and increased release of proinflammatory cytokines such as TNF- $\alpha^{7}$ and IL-6. ${ }^{7,8}$ Chronic consumption of excess fatty acids can induce a lipotoxic state, ${ }^{9}$ leading to adverse outcomes such as vascular events, ${ }^{10,11}$ insulin resistance, ${ }^{12}$ or circulating inflammatory cell recruitment. ${ }^{13}$

The innate immune system contributes to airway inflammation in asthma. ${ }^{14}$ Inflammation in asthma is heterogeneous. Although allergen-induced $\mathrm{T}_{\mathrm{H}} 2$ immune activation leads to airway eosinophilia, asthma can also involve neutrophilic inflammation that is associated with innate immune dysfunction. Increased sputum IL-8, neutrophil influx, and increased gene expression for TLR2 and TLR4 are observed. ${ }^{14}$ Airway neutrophils appear to be clinically important, because most severe forms of asthma ${ }^{15}$ involve elevated neutrophils, neutrophil counts increase with asthma severity, ${ }^{16}$ and sputum neutrophils negatively correlate with lung function and airflow obstruction in asthma. ${ }^{17}$ Thus, stimuli that activate innate immune responses, leading to increased airway neutrophilia, may be relevant to asthma development and progression.

Several studies have examined the role of dietary fat in asthma. A high fat intake and plasma triglyceride levels have been associated with airway hyperresponsiveness, ${ }^{18}$ asthma risk, ${ }^{19}$ and adult-onset wheeze. ${ }^{20}$ Other studies report that fat quality affects asthma outcomes. Trans fatty acids, ${ }^{21}$ margarine (a trans fatty acid source), ${ }^{22,23}$ and n-6 polyunsaturated fatty acids ${ }^{24}$ have been associated with increased asthma risk. Conversely, milk fat ${ }^{25,26}$ and n-3 polyunsaturated fatty acids or fish ${ }^{27,28}$ have been associated with decreased asthma risk in some but not all ${ }^{24}$ studies. Thus, epidemiologic associations link the amount and type of dietary fat consumption and asthma risk; however, the underlying mechanism of this association remains unclear.

We hypothesized that a high fat intake in asthma activates the innate immune response, causing an increase in systemic and 


\author{
Abbreviations used \\ ACQ: Asthma Control Questionnaire \\ AHF: Asthma high-fat \\ AHF-NonO: Asthma high-fat/high energy—nonobese \\ AHF-O: Asthma high-fat/high energy-obese \\ ALF: Asthma low-fat/low-energy \\ BMI: Body mass index \\ CRP: C-reactive protein \\ DRS: Dose response slope \\ eNO: Exhaled nitric oxide \\ FVC: Forced vital capacity \\ HCHF: Healthy controls high-fat \\ MUFA: Monounsaturated fatty acid \\ NF-кB: Nuclear factor- $\kappa B$ \\ PUFA: Polyunsaturated fatty acid \\ SFA: Saturated fatty acid \\ TE: Total energy \\ TLR: Toll-like receptor
}

airway inflammation and worsening clinical outcomes. The aim of this study was to examine the effect of a high-fat versus a lowfat meal on inflammation and clinical outcomes in asthma. We also aimed to determine whether the proinflammatory effects of a high-fat meal were modified by obesity or fat quality.

\section{METHODS \\ Study participants}

Nonobese (body mass index $[\mathrm{BMI}]<30 \mathrm{~kg} / \mathrm{m}^{2} ; \mathrm{n}=37$ ) and obese (BMI $\geq$ $\left.30 \mathrm{~kg} / \mathrm{m}^{2} ; \mathrm{n}=14\right)$ subjects older than 18 years with stable asthma were recruited. Before the study, subjects fasted for 12 hours and withheld shortacting and long-acting $\beta$-agonist medications. Exclusion criteria were current smoking (smoked within past 6 months), abnormal electrocardiogram at screening, pregnancy, diabetes mellitus, cardiac arrhythmia, angina, congestive heart failure, renal or hepatic failure, and systemic diseases. Asthma stability was defined as no exacerbation, respiratory tract infection, or oral corticosteroids in the past 4 weeks. Asthma control was assessed by using the Asthma Control Questionnaire (ACQ). ${ }^{29}$ Clinical asthma pattern was determined according to previous Global Initiative for Asthma recommendations. ${ }^{30}$ Nonobese healthy controls $(\mathrm{n}=21)$ were also recruited who had no respiratory symptoms, had never had a doctor's diagnosis of asthma, had normal lung function without airway hyperresponsiveness, and were steroidnaive. Atopy was determined by using skin allergen testing. Atopy was defined as an immediate reaction (wheal $\geq 3 \mathrm{~mm}$ ) to 1 or more of 19 common aeroallergens, carried out by using a 1:10 wt/vol dilution of Aspergillus fumigatus, Aspergillus mix, Penicillium, Alternaria tenuis, Dermatophagoides pteronyssinus, Dermatophagoides farinae, cockroach, peanut, hazelnut, wild oats, plantain, timothy, bent grass, blue grass, rye grass, cat hair, dog hair, feather mix, and horse dander, with histamine and saline as control (Bayer Australia Ltd, Pymble, Australia). All subjects were nonsmokers. Written informed consent was obtained from all subjects, and the study was approved by the Hunter New England Human Research Ethics Committee.

\section{Food challenge}

Nonobese subjects with asthma were randomized to consume a high-fat/ high-energy (AHF-NonO; $\mathrm{n}=19$ ) or low-fat/low-energy (ALF; $\mathrm{n}=18$ ) meal. Group assignment was determined by computer-generated random allocation, derived by an independent statistician. Initial treatment allocation was concealed from clinical staff, who allocated the next available number as participants entered the trial. Twenty-one nonobese healthy controls (HCHF) and 14 obese patients with asthma (AHF-O) also consumed a high-fat/highenergy meal. The high-fat meal contained total energy (TE) of $3846 \mathrm{~kJ}$ and
TABLE I. Plasma fatty acid concentrations (baseline and changes at 4 hours)

\begin{tabular}{lccc}
\hline $\begin{array}{l}\text { FAs } \\
\text { (mg/L) }\end{array}$ & Challenge type & $\mathbf{0 ~} \mathbf{~}$ & $\boldsymbol{\Delta} \mathbf{4} \mathbf{~}$ \\
\hline SFAs & High fat & $950 \pm 32$ & $112 \pm 20 \dagger^{*}$ \\
& Low fat & $804 \pm 75$ & $24 \pm 19$ \\
MUFAs & High fat & $835 \pm 36$ & $138 \pm 23 \dagger^{*}$ \\
& Low fat & $733 \pm 67$ & $47 \pm 23 \dagger$ \\
PUFAs & High fat & $1632 \pm 50$ & $77 \pm 22 \dagger$ \\
& Low fat & $2158 \pm 707$ & $25 \pm 20$ \\
Total FAs & High fat & $3416 \pm 109$ & $327 \pm 62 \dagger^{*}$ \\
& Low fat & $2869 \pm 253$ & $96 \pm 58$ \\
\hline
\end{tabular}

FA, Fatty acid.

Data are normally distributed and presented as means \pm SEMs, with groups compared by using the Student $t$ test.

$* P<.05$ compared with low fat.

$\dagger P<.05,4$ hours compared with baseline.

consisted of $79 \mathrm{~g}$ ( $33 \%$ of TE) carbohydrate, $39 \mathrm{~g}$ (18\% of TE) protein, and 48 $\mathrm{g}$ (49\% of TE) total fat, including $20.5 \mathrm{~g}$ (21\% of TE) saturated fat. The low-fat meal contained total energy (TE) of $806 \mathrm{~kJ}$ and consisted of $32 \mathrm{~g}$ (64\% of TE) carbohydrate, $10 \mathrm{~g}$ ( $21 \%$ of TE) protein, and $3.4 \mathrm{~g}$ (15\% of TE) total fat, including $2.2 \mathrm{~g}$ ( $10 \%$ of TE) saturated fat. Neither subjects nor investigators were blind to the treatments. However, primary outcome assessments (induced sputum markers) were conducted blind to both subjects and investigators. At baseline (time $=0$ ), prebronchodilator lung function was measured. A hypertonic saline challenge was conducted, and at the conclusion of the challenge, $200 \mu \mathrm{g}$ salbutamol was administered to all subjects. The study meal was consumed within 15 minutes, and then lung function was monitored at 2 , 3 , and 4 hours, with no additional administration of salbutamol. Blood was collected at $0,2,3$, and 4 hours, and induced sputum was collected at 0 and 4 hours. Exhaled nitric oxide (eNO) was also measured at 0 and 4 hours (NIOX, Aerocrine AB, Solna, Sweden).

\section{Trans fatty acid meal challenge}

Another group of subjects with asthma were assigned, via computergenerated random sequence, to receive a high-trans $(n=5)$ or nontrans $(n=5)$ fatty acid meal. The meals were equivalent in energy, total fat, and saturated fat content, with each containing approximately $2700 \mathrm{~kJ}$, with $35 \%$ energy from fat and $9 \%$ energy from saturated fat. The trans fatty acid content of the meals was $5.2 \mathrm{~g}$ versus $<0.3 \mathrm{~g}$, in trans versus nontrans meals, respectively. Sputum was induced at 0 and 4 hours.

\section{Hypertonic saline challenge}

Spirometry (Minato Autospiro AS-600; Minato Medical Science, Osaka, Japan) and combined bronchial provocation and sputum induction with hypertonic saline (4.5\%) were performed as previously described. ${ }^{31}$ After baseline spirometry and expectoration instruction, hypertonic saline was administered for increasing periods ( 30 seconds, 1 minute, 2 minutes, 4 minutes, 4 minutes, 4 minutes) via an ultrasonic nebulizer (ULTRA-NEB Model 2000; De Vilbiss Healthcare Inc, Somerset, Pa) with a Hans Rudolph 2-way valve (Hans Rudolph Inc, Shawnee, Kan). Spirometry was measured 1 minute after each dose, and participants were asked to expectorate after each dose of hypertonic saline. Salbutamol $200 \mu \mathrm{g}$ was administered via pressurized inhaler and valved holding chamber if $\mathrm{FEV}_{1}$ dropped below $15 \%$ of baseline. These subjects were considered to be airway hyperresponsive. In subjects for whom $\mathrm{FEV}_{1}$ did not decrease by $15 \%$ from baseline, salbutamol $200 \mu \mathrm{g}$ was administered at the maximum nebulization time of 15 minutes. Spirometry was performed according to American Thoracic Society standards, with the largest forced vital capacity (FVC) and $\mathrm{FEV}_{1}$ measured from a series of at least 3 usable forced expiratory curves. ${ }^{3}$

\section{Sputum processing and analysis}

Induced sputum was collected, and mucus plugs were separated from the salivary portion of the sample. Mucus plugs were dispersed with dithiothreitol, 
TABLE II. Subject characteristics at baseline

\begin{tabular}{|c|c|c|c|c|}
\hline Clinical characteristic & HCHF & ALF & AHF-NonO & AHF-O \\
\hline $\mathrm{n}$ & 21 & 18 & 19 & 14 \\
\hline Age $(y)^{*}$ & $49.6 \pm 4.6$ & $41.7 \pm 3.2$ & $50.9 \pm 4.3$ & $56.5 \pm 4.3$ \\
\hline $\operatorname{Sex}(M / F)$ & $9 / 12$ & $7 / 11$ & $9 / 10$ & $4 / 10$ \\
\hline Atopy (yes/no) & $9 / 12 \|$ & $15 / 3$ & $16 / 3$ & $10 / 4$ \\
\hline $\mathrm{ACQ}^{*}$ & NA & $0.7 \pm 0.5$ & $0.7 \pm 0.6$ & $0.9 \pm 0.4$ \\
\hline $\begin{array}{l}\text { Asthma pattern } \\
\text { (intermittent } / \mathrm{mild} / \text { moderate/severe persistent) }\end{array}$ & NA & $5 / 4 / 5 / 4$ & $8 / 1 / 9 / 1$ & $3 / 4 / 3 / 4$ \\
\hline $\mathrm{PD}_{15}(\mathrm{~mL})^{* \dagger}$ & NA & $0.64 \pm 0.45$ & $0.70 \pm 0.47$ & $0.67 \pm 0.66$ \\
\hline AHR (yes/no) & $0 / 21$ & $11 / 7$ & $13 / 6$ & $6 / 8$ \\
\hline DRS ( $\%$ fall $\mathrm{FEV}_{1} / \mathrm{mL}$ saline $) \dagger$ & $0.2(0.0-0.4) \|$ & $1.8(0.5-6.1)$ & $1.6(0.6-4.1)$ & $0.9(0.2-1.8)$ \\
\hline
\end{tabular}

$A H R$, Airway hyperresponsive; $F$, female; $I C S$, inhaled corticosteroid; $M$, male; $N A$, not applicable.

*Data are normally distributed and presented as means \pm SEMs, with group comparisons performed by using the ANOVA test, with Bonferroni post hoc testing.

$\dagger$ Data are nonparametric, presented as median (quartile 1-quartile 3), with group comparisons performed by using the Kruskal-Wallis test, with Dunn post hoc testing.

$\$ \mathrm{PD}_{15}$, Provocation dose resulting in $15 \%$ fall in baseline $\mathrm{FEV}_{1}$, expressed as geometric mean $\pm \log \mathrm{SD}$.

$\S P<.05$ versus $\mathrm{HCHF}$, AHF-NonO, and ALF.

$\| P<.05$ versus AHF-NonO, AHF-O, and ALF.

and a total and differential cell count of leukocytes was performed, as previously described. ${ }^{31}$ For TLR4 gene expression analysis, $100 \mu \mathrm{L}$ selected sputum was added to Buffer RLT (Qiagen, Hilden, Germany) and stored at $-80^{\circ} \mathrm{C}$. RNA was extracted and quantified and gene expression of TLR4 evaluated in a duplex reaction by using the ABI 7500 Real Time PCR system (Applied Biosystems, Mulgrave, Victoria, Australia) as previously described. ${ }^{14}$ The expression of $T L R 4$ was calculated relative to a positive calibrator and normalized to the endogenous control.

\section{Blood processing and analysis}

Blood was collected in EDTA tubes and centrifuged at $4{ }^{\circ} \mathrm{C}, 3000 \mathrm{~g}$, for 10 minutes, and plasma was stored at $-80^{\circ} \mathrm{C}$. Plasma fatty acid concentrations were analyzed by using gas chromatography as previously described. ${ }^{32}$ Commercial ELISAs were used to measure IL- 6 and TNF- $\alpha$ (R\&D Systems, Minneapolis, Minn) and high-sensitivity C-reactive protein (CRP; MPBiomedicals, Solon, Ohio).

\section{Statistical analysis}

Results were analyzed by using Minitab version 15 for Windows (Minitab Inc, State College, Pa). Statistical comparisons between groups at each time point were performed by using 1-way ANOVA followed by Bonferroni post hoc testing for parametric data or Kruskal-Wallis followed by Dunn post hoc testing for nonparametric data. An additional analysis was performed comparing the combined asthma high-fat groups (AHF) with the ALF group. The means \pm SEMs are reported for normally distributed data; for nonparametric data the medians (quartiles 1-3) are reported. Associations between variables were examined by using the Pearson correlation coefficient for normally distributed data and the Spearman rank correlation coefficient for nonparametric data. Significance was accepted if $P<05$. Some of the results included in this article have been published previously in abstract form. ${ }^{33}$

\section{RESULTS}

Compared with baseline, there was a significant increase in plasma levels of total fatty acids, saturated fatty acids (SFAs), monounsaturated fatty acids (MUFAs), and polyunsaturated fatty acids (PUFA) at 4 hours after the high-fat challenge (Table I). The high-fat challenge led to a significantly greater increase in plasma levels of total fatty acids, SFAs, and MUFAs than the low-fat challenge (Table I).
There were no significant differences in age or sex of each of the groups (Table II). There was no difference in ACQ, asthma pattern, maintenance inhaled corticosteroid dose, dose response slope (DRS), or provocation dose resulting in $15 \%$ fall in baseline $\mathrm{FEV}_{1}$ (pd15) across the asthmatic groups. As expected, the median DRS was lower and there was a lower proportion of atopic subjects in the HCHF compared with the asthma groups (Table II).

Administration of salbutamol in the ALF group led to a significant improvement in \% predicted $\mathrm{FEV}_{1}$ at 2 and 3 hours compared with baseline (prebronchodilator $\%$ predicted $\mathrm{FEV}_{1}$; Table III; Fig 1, A). In the AHF-NonO group, there was a smaller improvement in $\%$ predicted $\mathrm{FEV}_{1}$ at 2 and 3 hours, and in the AHF-O group there was a small improvement in $\%$ predicted $\mathrm{FEV}_{1}$ at 2 hours only (Table III). At 3 hours, the improvement in $\%$ predicted $\mathrm{FEV}_{1}$ was significantly less in the AHF-O group than in the ALF group (Table III). A similar pattern occurred with $\mathrm{FEV}_{1} / \mathrm{FVC}$. In the ALF group, administration of salbutamol led to an improvement in $\mathrm{FEV}_{1} / \mathrm{FVC}$ compared with baseline (prebronchodilator $\mathrm{FEV}_{1} / \mathrm{FVC}$ ) at 2 hours, and this was maintained at 3 and 4 hours (Table III; Fig 1, B). In the AHF-NonO and $\mathrm{AHF}-\mathrm{O}$ groups, there were small improvements in $\mathrm{FEV}_{1} /$ FVC at 2 hours only. At 4 hours, the increase in $\mathrm{FEV}_{1} / \mathrm{FVC}$ was significantly higher in the ALF compared with the AHF-NonO, AHF-O, and HCHF groups (Table III).

At baseline, sputum \% neutrophils were similar across all groups, whereas \% eosinophils were higher in the asthma groups compared with the HCHF group (Table IV). At 4 hours postmeal, the fold increase in TLR4 mRNA expression in the AHF groups was significantly higher than in the ALF group, in which it did not increase compared with baseline (Fig 2, A). Also at 4 hours after the food challenge, there was a significant increase in sputum $\%$ neutrophils compared with baseline in each of the high-fat groups. The increase in sputum \% neutrophils in the AHF groups was significantly different from the ALF group, in which it did not increase compared with baseline (Fig 2,B). There were no dietrelated changes in eNO or sputum $\%$ eosinophils.

At baseline, concentrations of IL- 6 and CRP were higher in the AHF-O group compared with the HCHF and ALF groups (Table V). There were small increases in plasma IL-6 compared with baseline in the AHF-O group at 2, 3, and 4 hours and in 
TABLE III. Lung function (baseline and changes at 2, 3, and 4 hours)

\begin{tabular}{|c|c|c|c|c|c|c|c|c|c|}
\hline Lung function variable & Diet group & $\mathbf{O h}$ & $P$ value & $\Delta 2 \mathrm{~h} \S$ & $P$ value & $\Delta \mathbf{3 ~ h \S}$ & $P$ value & $\Delta 4 \mathrm{~h} \S$ & $P$ value \\
\hline $\mathrm{FEV}_{1}$ & $\mathrm{HCHF}$ & $102.1 \pm 2.4$ & .001 & $2.5 \pm 0.7$ & .021 & $0.4 \pm 1.1 *$ & .004 & $-0.1 \pm 0.5$ & .207 \\
\hline \multirow[t]{3}{*}{$\%$ predicted } & ALF & $82.9 \pm 4.2 \dagger$ & & $6.6 \pm 1.7 \ddagger$ & & $6.2 \pm 1.6 \ddagger$ & & $3.8 \pm 1.5$ & \\
\hline & AHF-NonO & $84.2 \pm 3.5 \dagger$ & & $6.5 \pm 1.2 \ddagger$ & & $3.8 \pm 0.9 \ddagger$ & & $1.5 \pm 1.5$ & \\
\hline & AHF-O & $85.6 \pm 6.2 \dagger$ & & $2.9 \pm 1.0 \neq$ & & $0.5 \pm 1.2 *$ & & $1.3 \pm 1.7$ & \\
\hline FVC, $\%$ predicted & $\mathrm{HCHF}$ & $106.5 \pm 2.4$ & .109 & $-0.9 \pm 1.08$ & .086 & $-1.0 \pm 0.8$ & .075 & $-0.9 \pm 0.6$ & .410 \\
\hline \multirow[t]{3}{*}{$\%$ predicted } & ALF & $98.8 \pm 3.2$ & & $4.1 \pm 1.9 \ddagger$ & & $2.8 \pm 1.5$ & & $1.3 \pm 1.2$ & \\
\hline & AHF-NonO & $101.2 \pm 2.8$ & & $1.8 \pm 1.5$ & & $1.2 \pm 0.7 \ddagger$ & & $-0.4 \pm 1.3$ & \\
\hline & AHF-O & $95.3 \pm 5.0$ & & $1.0 \pm 1.2$ & & $-0.4 \pm 1.5$ & & $0.3 \pm 0.8$ & \\
\hline \multirow[t]{4}{*}{$\mathrm{FEV}_{1} / \mathrm{FVC} \%$} & $\mathrm{HCHF}$ & $78.7 \pm 1.3$ & .002 & $2.3 \pm 0.4$ & .444 & $1.3 \pm 0.6$ & .059 & $0.7 \pm 0.3^{*}$ & .002 \\
\hline & ALF & $69.9 \pm 2.5 \dagger$ & & $3.3 \pm 0.7 \hbar$ & & $3.5 \pm 0.8 \%$ & & $3.8 \pm 1.0 \ddagger$ & \\
\hline & AHF-NonO & $67.7 \pm 2.1 \dagger$ & & $2.6 \pm 0.5 \ddagger$ & & $2.2 \pm 0.7$ & & $1.1 \pm 0.6^{*}$ & \\
\hline & AHF-O & $72.2 \pm 2.7$ & & $2.0 \pm 0.5 \ddagger$ & & $0.9 \pm 0.7$ & & $0.1 \pm 0.7^{*}$ & \\
\hline
\end{tabular}

Data are normally distributed, presented as means \pm SEMs, with group comparisons performed by using the ANOVA test, with Bonferroni post hoc testing.

$* P<.05$ versus ALF.

$\dagger P<.05$ versus HCHF.

$\ddagger P<.05$ compared with baseline.

$\S \Delta 2 \mathrm{~h}, \Delta 3 \mathrm{~h}$, and $\Delta 4 \mathrm{~h}$ is the change in $\%$ predicted values at each time point-for example, $\Delta 2 \mathrm{~h}$ for $\%$ predicted $\mathrm{FEV}_{1}$ is $\left(\%\right.$ predicted FEV $\mathrm{f}_{1} \mathrm{~h}-\%$ predicted $\mathrm{FEV} \mathrm{F}_{1}$ at $\left.0 \mathrm{~h}\right)$.

the HCHF group at 4 hours. There was also an increase in plasma CRP compared with baseline in the AHF-O group at 2 hours, and this was significantly different from the HCHF group (Table V). No differences in key outcomes were identified in subjects with and without atopy, although the number of subjects in these comparisons was small and the study was not powered to detect such differences.

There were several significant correlations between the increases in plasma fatty acids and changes in lung function and systemic and airway inflammation (Table VI). The increase in total fatty acids and PUFAs at 4 hours was associated with an increase in TNF- $\alpha$ at 3 hours. The increase in total fatty acids, SFAs, and MUFAs at 4 hours was also associated with the increase in sputum \% neutrophils at 4 hours. Furthermore, the increase in total fatty acids, SFAs, and MUFAs at 4 hours was inversely associated with the change in $\% \mathrm{FEV}_{1}$ at 4 hours, and the increases in total fatty acids, SFAs, MUFAs, and PUFAs at 4 hours were inversely associated with $\% \mathrm{FVC}$ and $\mathrm{FEV}_{1} / \mathrm{FVC}$ at 4 hours (Table VI).

In the trans fatty acid meal challenge, the change in sputum $\%$ neutrophils was significantly different after the trans compared with the nontrans meals (mean \pm SEM, $29.4 \% \pm 6.7 \%$ vs $1.7 \%$ $\pm 9.8 \% ; P=.048)$. Consumption of the trans fatty acid meal led to a significant increase in sputum $\%$ neutrophils compared with baseline, whereas there was no change in sputum \% neutrophils compared with baseline after the nontrans meal.

\section{DISCUSSION}

This is the first study to investigate the direct effect of dietary fat on systemic and airway inflammation in asthma. We have demonstrated that in patients with asthma, consumption of a single high-fat meal leads to increased circulating fatty acid levels, and this corresponds with an increase in induced sputum $\%$ neutrophils and TLR 4 mRNA expression in sputum cells. This fatinduced inflammation corresponds with attenuation of airway bronchodilator recovery, which correlates with the increase in plasma fatty acid concentrations.

The increase in airway neutrophilia that we observed after the high-fat meal provides the first evidence that airway inflammation can be modified by dietary fat consumption. Various studies
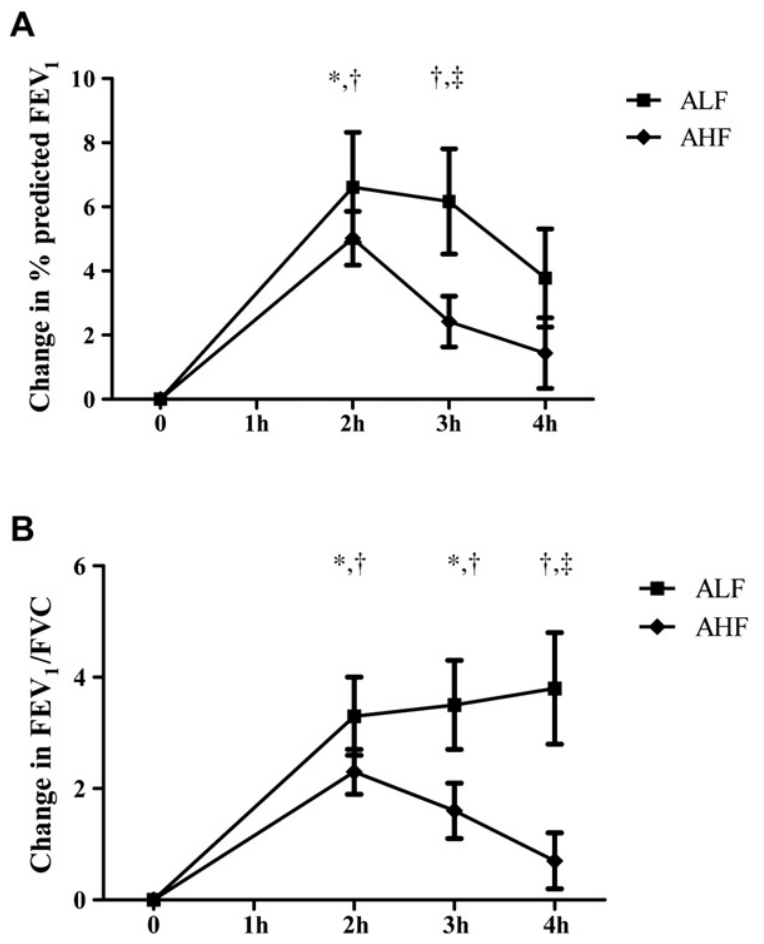

FIG 1. In subjects with asthma, changes in lung function monitored over 4 hours after administration of bronchodilator and consumption of the high fat (AHF) and low fat (ALF) food challenges. A, Change in \% predicted FEV ( $\%$ predicted $\mathrm{FEV}_{1}$ at 2,3 , and 4 hours - \% predicted $\mathrm{FEV}_{1}$ at 0 hour). B, Change in $\mathrm{FEV}_{1} / \mathrm{FVC}\left(\mathrm{FEV}_{1} / \mathrm{FVC}\right.$ at 2,3 , and 4 hours $-\mathrm{FEV}_{1} / \mathrm{FVC}$ at 0 hour). ${ }^{*} P<.05$, AHF versus baseline; $\dagger P<.05$, ALF versus baseline; $₫ P<.05$, AHF versus ALF.

have used an acute fat challenge model to investigate the systemic inflammatory effects of dietary fat ${ }^{34}$ in nonasthmatic groups. Although there is some heterogeneity in the data, evidence of a fat challenge activating the innate immune responses includes upregulation of TLR2, TLR $4,{ }^{4}$ and NF- $\mathrm{\kappa B}{ }^{5,6}$ activity; an increase in proinflammatory cytokines, including TNF- $\alpha{ }^{7}$ IL-6, ${ }^{7,8}$ and $\mathrm{CRP}^{5}$; and an increase in circulating neutrophils, IL-8, and hydroperoxides associated with impaired endothelial 
TABLE IV. Airway inflammation (baseline and changes at 4 hours)

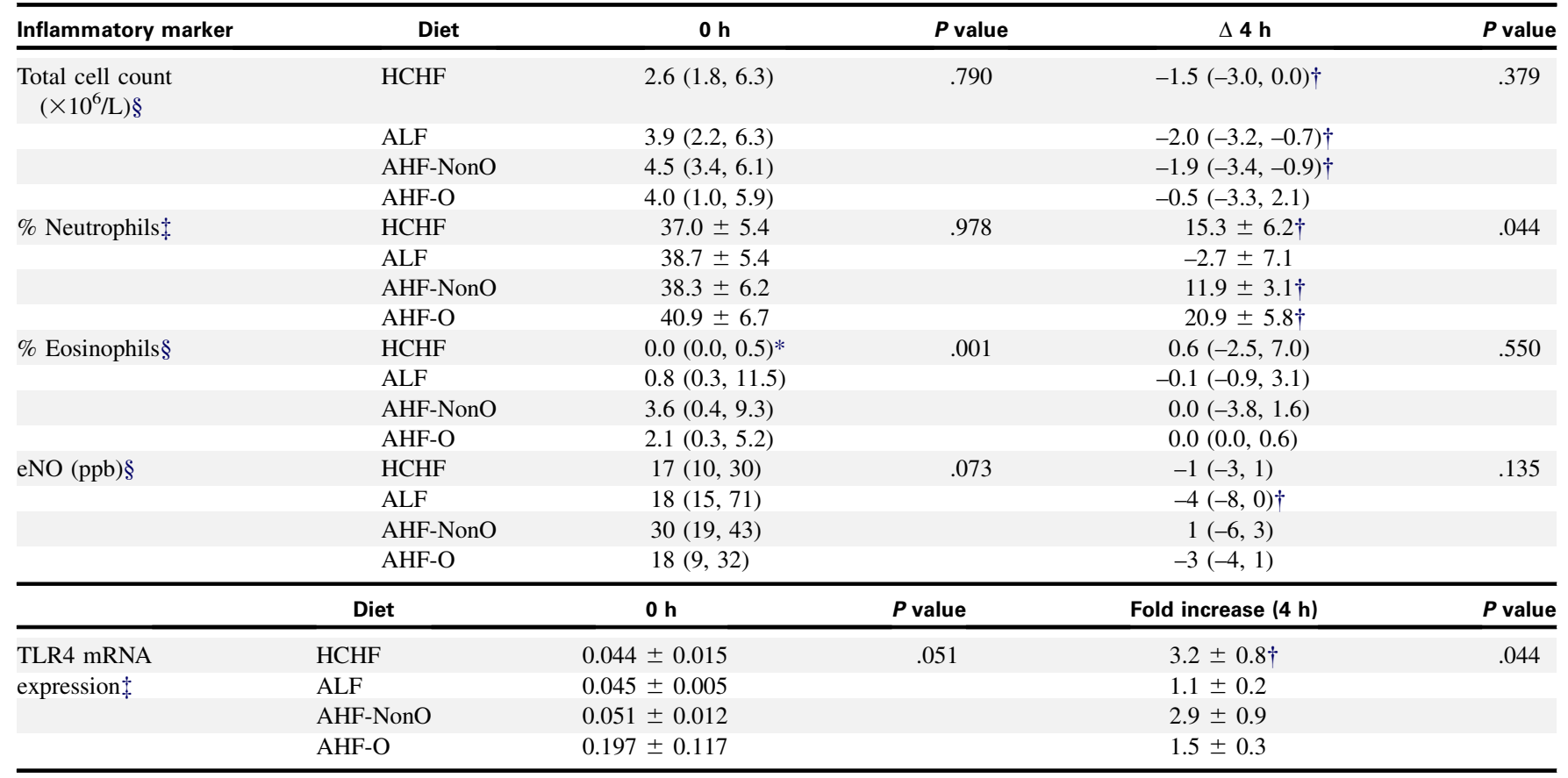

$* P<.05$ versus ALF, AHF-NonO, and AHF-O.

$\dagger P<.05$ compared with baseline.

$\ddagger$ Data are normally distributed and presented as means \pm SEMs, with group comparisons performed by using the ANOVA test, with Bonferroni post hoc testing.

$\S$ Data are nonparametric, presented as median (quartile 1, quartile 3), with group comparisons performed by using the Kruskal-Wallis test, with Dunn post hoc testing.

function. ${ }^{13}$ This study is the first to use the acute challenge model to investigate effects of dietary fat on airway inflammation in asthma.

We have also shown that in patients with asthma, dietary fat increases TLR4 mRNA expression in sputum cells. Although our data support the hypothesis that TLR4 activation has a central role in fat-induced inflammation, other receptors are also likely to be involved. A study by Zhao et $\mathrm{al}^{35}$ demonstrated that nucleotidebinding oligomerization domain-containing proteins recognize saturated fatty acids in intestinal epithelial cells, resulting in modulation of NF- $\kappa$ B and IL- 8 gene expression. The relevance of innate immune receptors in the airways is an important area for future research.

We did not see any differences in eNO levels after the high-fat meal in our study. eNO is a marker of eosinophilic disease rather than a general marker of airway inflammation in asthma. ${ }^{1} \mathrm{Be}$ cause the inflammatory changes that we observed involved increases in airway neutrophils, with no changes in sputum eosinophils, it is not surprising that eNO levels were unchanged. Another study using an acute fat challenge in healthy controls has recently reported a small increase in eNO production postmeal. ${ }^{36}$ Although the increase was statistically significant, the size of the increase was very small (mean, $3.6 \mathrm{ppb}$ ) and is unlikely to be clinically significant. Atopy is also associated with eosinophilic, rather than neutrophilic, infiltration into the airways. Hence, it might be expected that subjects with nonatopic disease may be more susceptible to fat-induced inflammation. There were no differences in our key outcomes in subjects with and without atopy. However, the number of subjects included in these comparisons is small, and the study is not powered to detect such differences. This would be an interesting avenue for future research.
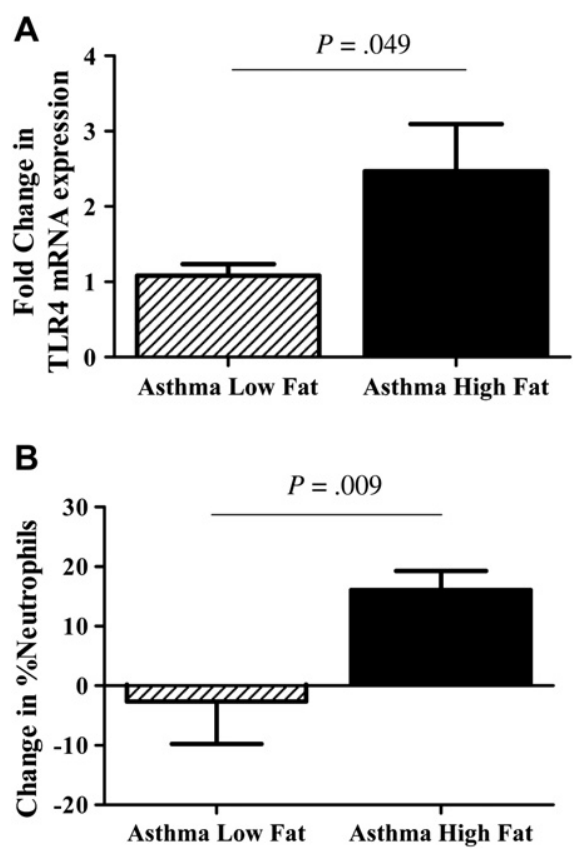

FIG 2. In subjects with asthma, changes in innate immune activity at 4 hours after administration of bronchodilator and consumption of the high fat (AHF) and low fat (ALF) food challenges. A, Fold change in induced sputum cell TLR4 mRNA expression. B, Change in induced sputum percent neutrophils.

We also observed that the high-fat meal impaired bronchodilator recovery in asthma by attenuating the increase in \% predicted $\mathrm{FEV}_{1}$ and $\mathrm{FEV}_{1} / \mathrm{FVC}$ in the AHF versus the ALF groups. Our study design required subjects to withhold 
TABLE V. Systemic inflammation (baseline and changes at 2, 3, and 4 hours)

\begin{tabular}{|c|c|c|c|c|c|c|c|c|c|}
\hline Inflammatory marker & Diet group & $\mathbf{O} \mathbf{h}$ & $P$ value & $\Delta 2 \mathrm{~h}$ & $P$ value & $\Delta \mathbf{3 h}$ & $P$ value & $\Delta 4 \mathrm{~h}$ & $P$ value \\
\hline \multirow[t]{4}{*}{ IL-6 (pg/mL) } & $\mathrm{HCHF}$ & $0.8(0.7,1.2)$ & .001 & $0.0(-0.3,0.3)$ & .118 & $0.2(-0.3,0.9)$ & .119 & $0.3(-0.1,0.7) \ddagger$ & .035 \\
\hline & ALF & $1.2(0.7,1.6)$ & & $0.0(-0.2,0.3)$ & & $0.0(-0.1,0.4)$ & & $0.1(-0.1,0.4)$ & \\
\hline & AHF-NonO & $1.3(1.1,2.4) \dagger$ & & $0.0(-0.3,0.3)$ & & $0.1(-0.2,0.8)$ & & $0.0(-0.2,0.6)$ & \\
\hline & AHF-O & $2.0(1.6,2.8)^{* \dagger}$ & & $0.2(0.1,1.2) \ddagger$ & & $0.4(0.2,1.4) \ddagger$ & & $0.8(0.3,1.2) \dagger$ & \\
\hline \multirow[t]{4}{*}{ TNF- $\alpha(\mathrm{pg} / \mathrm{mL})$} & $\mathrm{HCHF}$ & $1.4(1.4,2.1)$ & .578 & $0.0(-0.2,0.1)$ & .287 & $-0.1(-0.4,0.0) \ddagger$ & .625 & $-0.1(-0.3,0.0) \ddagger$ & .955 \\
\hline & ALF & $1.6(1.2,2.3)$ & & $-0.2(-0.5,0.1)$ & & $-0.3(-0.6,0.1) \ddagger$ & & $0.0(-0.4,0.2)$ & \\
\hline & AHF-NonO & $1.4(0.9,1.9)$ & & $-0.2(-0.4,0.0) \ddagger$ & & $-0.2(-0.4,0.1)$ & & $-0.1(-0.4,0.2)$ & \\
\hline & AHF-O & $1.2(0.9,2.1)$ & & $-0.1(-0.3,0.2)$ & & $-0.1(-0.3,0.1)$ & & $0.0(-0.4,0.2)$ & \\
\hline \multirow[t]{4}{*}{$\mathrm{CRP}(\mathrm{mg} / \mathrm{mL})$} & $\mathrm{HCHF}$ & $1.6(0.8,2,8)$ & .001 & $-0.1(-0.3,0.1)$ & .038 & $0.0(-0.3,0.1)$ & .631 & $-0.3(0.1,0.2)$ & .904 \\
\hline & ALF & $1.3(0.4,3.4)$ & & $0.0(-0.2,0.1)$ & & $-0.1(-0.2,0.3)$ & & $0.1(-0.1,0.2)$ & \\
\hline & AHF-NonO & $2.6(0.9,8.9)$ & & $0.0(-0.3,0.3)$ & & $-0.2(-0.8,0.1)$ & & $0.0(-0.5,0.1)$ & \\
\hline & AHF-O & $7.0(4.3,13.0)^{* \dagger}$ & & $0.8(-0.1,1.5) \dagger$ & & $0.0(-1.1,0.8)$ & & $0.3(-0.5,1.8)$ & \\
\hline
\end{tabular}

Data are nonparametric, presented as median (quartile 1, quartile 3), with group comparisons performed by using the Kruskal-Wallis test, with Dunn post hoc testing.

$* P<.05$ versus ALF.

$\dagger P<.05$ versus $\mathrm{HCHF}$.

$\ddagger P<.05$ compared with baseline.

short-acting and long-acting $\beta$-agonists before the study. At baseline, subjects then underwent a hypertonic saline challenge, followed by the administration of salbutamol. In the subsequent 3-hour period, subjects in the ALF group had a mean improvement in $\%$ predicted $\mathrm{FEV}_{1}$ of 6.2 compared with prebronchodilator $\%$ predicted $\mathrm{FEV}_{1}$. However, for subjects in the AHF group, the recovery after bronchodilator administration was attenuated in both magnitude and duration, and only a small increase in $\%$ predicted $\mathrm{FEV}_{1}$ was observed. Our data suggest that the attenuation of $\mathrm{FEV}_{1}$ recovery in response to $\beta$-agonist was worse in the obese subjects with asthma. It is unclear why this difference would exist, because the inflammatory response to fat was similar in obese and nonobese subjects with asthma. However, it has previously been demonstrated that obesity leads to a worsening of asthma control and reduced responsiveness to treatment. ${ }^{37}$ This observation requires further investigation.

The role of dietary fat in this differential bronchodilator recovery is reinforced by the consistent inverse correlations between change in lung function and change in plasma fatty acid levels. The effect of dietary fat on the response to a bronchodilator delivered by aerosol has not been reported previously. Airway inflammatory responses may be contributing to suppressed lung function, because sputum neutrophils have previously been shown to correlate negatively with lung function $\left(\% \mathrm{FEV}_{1}\right)$ and airflow obstruction in asthma. ${ }^{17}$ Fatty acids may also modify bronchodilator recovery by other mechanisms. A study of transdermal delivery of bronchodilators found that longer-chain fatty acids are more easily incorporated into cell membranes; however, their greater lipophilicity reduces membrane permeability. ${ }^{38}$ In our study, the high fat load was dominated by longer-chain fatty acids (C16, C18, and C20), which may have reduced penetration of bronchodilator into the airway epithelium. Alternatively, it is possible that these exogenous fatty acids modulate the sympathetic nervous system, acting as $\beta_{2}$-adrenergic receptor antagonists, thereby inhibiting the bronchodilator effect. The mechanisms involved need further investigation, because the observation that a high-fat meal attenuates bronchodilator recovery has very important implications for asthma management.

There were few significant differences in systemic inflammatory markers in our study. Small increases in plasma IL-6 and CRP were observed in the AHF-O group. In the subjects with
TABLE VI. Correlations among change $(\Delta)$ in plasma fatty acids, systemic and airway inflammatory markers, and lung function in nonobese subjects with asthma

\begin{tabular}{|c|c|c|c|c|c|}
\hline \multirow[b]{2}{*}{ Predictor } & \multicolumn{5}{|c|}{ Outcome } \\
\hline & $\begin{array}{c}\Delta \text { TNF- } \alpha \\
(3 \mathrm{~h})\end{array}$ & $\begin{array}{c}\Delta \% \mathrm{~N} \\
(4 \mathrm{~h})\end{array}$ & $\begin{array}{c}\Delta \text { FEV }_{1} \\
(4 \mathrm{~h})\end{array}$ & $\begin{array}{c}\Delta \text { FVC \% } \\
\text { (4 h) }\end{array}$ & $\begin{array}{c}\Delta \mathrm{FEV}_{1} / \mathrm{FVC} \\
(4 \mathrm{~h})\end{array}$ \\
\hline \multicolumn{6}{|c|}{$\Delta$ SFA $(4 \mathrm{~h})$} \\
\hline$r$ & 0.349 & 0.451 & -0.443 & -0.532 & -0.383 \\
\hline$P$ & .064 & .031 & .010 & .001 & .028 \\
\hline \multicolumn{6}{|c|}{$\Delta$ MUFA $(4 \mathrm{~h})$} \\
\hline$r$ & 0.333 & 0.512 & -0.407 & -0.472 & -0.389 \\
\hline$P$ & .078 & .013 & .019 & .006 & .025 \\
\hline \multicolumn{6}{|c|}{$\Delta$ PUFA $(4 \mathrm{~h})$} \\
\hline$r$ & 0.479 & 0.382 & -0.371 & -0.332 & -0.455 \\
\hline$P$ & .009 & .072 & .034 & .059 & .008 \\
\hline \multicolumn{6}{|c|}{$\Delta$ Total FA $(4 \mathrm{~h})$} \\
\hline$r$ & 0.394 & 0.490 & -0.421 & -0.464 & -0.420 \\
\hline$P$ & .034 & .018 & .007 & .007 & .015 \\
\hline
\end{tabular}

$F A$, Fatty acid; $N$, neutrophils.

asthma, there was also a correlation between the increases in plasma fatty acid levels and TNF- $\alpha$ at 3 hours. The systemic inflammatory mediators that we evaluated, including IL- $6,{ }^{39}$ $\mathrm{CRP}^{40}$ and TNF- $\alpha,{ }^{39}$ have previously been shown to be elevated after a high-fat meal. Although there were small increases in these mediators in our study, we observed a much stronger inflammatory response in the airways. Thus, it appears that the results we have observed are not simply the result of overspill of systemic inflammatory mediators into the airways.

The differential responses that we observed as a result of the trans versus nontrans fatty acid meals demonstrate the different innate immune responses that occur in response to fatty acids of different structures. It has previously been reported that induction of NF- $\kappa \mathrm{B}$ activity, ${ }^{41} \mathrm{CRP}$ levels, ${ }^{42}$ and TLR activity vary according to fat type, ${ }^{43,44}$ with SFA having the most potent inflammatory actions. We chose to examine the effect of trans fatty acids on airway inflammation because they have been shown to have systemic proinflammatory effects. ${ }^{45}$ Trans fatty acids exist primarily because of hydrogenation of fats in food manufacturing processes. Because of negative health outcomes associated with trans fatty acids, they are being eliminated from the food supply. 
This study provides further evidence of the proinflammatory effects of trans fatty acids and demonstrates that the inflammatory effects of dietary fat on airway inflammation vary with fat quality. This is also an important area for future research.

The nutritional composition of the high-fat meal was mixed, containing fats of different quality and degree of saturation, as well as other macronutrients, all of which may have influenced the inflammatory response. This meal was chosen because it represents a dietary pattern that is typically associated with westernized diets and has been demonstrated to increase asthma risk. ${ }^{46,47}$ Nonetheless, our data suggests that the dietary fat was important to the effects that we observed, because gene expression of $T L R 4$, which is activated by nutritional fatty acids, was increased after the high-fat meal. In addition, the high-fat meal led to significant increases in plasma fatty acids compared with baseline, which were correlated with the increases in airway inflammation and suppression of lung function. Thus we can conclude that the increase in circulating fatty acids levels have contributed to the effects that we have observed. A limitation of the study is that the data presented are the result of a single meal. Further research is needed to confirm whether chronic consumption of high-fat foods would have similar sustained effects. Nonetheless, we provide evidence for a mechanism that may be contributing to the recent epidemiologic reports of an association between fast food and asthma risk. ${ }^{46,47}$

In summary, this study demonstrates that a high-fat/highenergy meal augments airway inflammation in asthma, resulting in an increased proportion of sputum neutrophils and increased TLR4 mRNA expression in sputum cells, suggesting activation of the innate immune response by fatty acids in the airways. This fatinduced inflammation is also associated with a suppression of the airway response to bronchodilator, with the extent of this suppression correlating with the increase in fatty acid concentrations. We conclude that dietary fat leads to airway inflammation in asthma, and worse clinical outcomes. Strategies aimed at modifying dietary fat intake may be useful in reducing airway neutrophilia, which is known to have clinical significance in asthma.

We acknowledge the staff in Respiratory and Sleep Medicine, Hunter Medical Research Institute, including Joanne Smart, Amber Smith, Katie Baines, and Lakshitha Gunawardhana, who collected and processed the samples and performed the laboratory analysis.

Clinical implications: Dietary fat leads to airway inflammation in asthma and impairs bronchodilator recovery. This suggests that strategies aimed at modifying dietary fat intake may be important in asthma management.

\section{REFERENCES}

1. Ajuwon KM, Spurlock ME. Palmitate activates the NF-kappaB transcription factor and induces IL-6 and TNFalpha expression in 3T3-L1 adipocytes. J Nutr 2005; 135 1841-6.

2. Sinha S, Perdomo G, Brown NF, O'Doherty RM. Fatty acid-induced insulin resistance in L6 myotubes is prevented by inhibition of activation and nuclear localization of nuclear factor kappa B. J Biol Chem 2004;279:41294-301.

3. Shi H, Kokoeva MV, Inouye K, Tzameli I, Yin H, Flier JS. TLR4 links innate immunity and fatty acid-induced insulin resistance. J Clin Invest 2006;116:3015-25.

4. Ghanim H, Sia CL, Upadhyay M, Korzeniewski K, Viswanathan P, Abuaysheh S, et al. Orange juice neutralizes the proinflammatory effect of a high-fat, high-carbohydrate meal and prevents endotoxin increase and Toll-like receptor expression. Am J Clin Nutr 2010;91:940-9.

5. Aljada A, Mohanty P, Ghanim H, Abdo T, Tripathy D, Chaudhuri A, et al. Increase in intracellular nuclear factor $\kappa \mathrm{B}$ and decrease in inhibitor $\kappa \mathrm{B}$ in mononuclear cells after a mixed meal: evidence for a proinflammatory effect. Am J Clin Nutr 2004 79:682-90

6. Patel C, Ghanim H, Ravishankar S, Sia CL, Viswanathan P, Mohanty P, et al. Prolonged reactive oxygen species generation and nuclear factor- $\mathrm{KB}$ activation after a high-fat, high-carbohydrate meal in the obese. J Clin Endocrinol Metab 2007;92 4476-9.

7. Nappo F, Esposito K, Cioffi M, Guigliano G, Molinari AM, Paolisso G, et al. Postprandial endothelial activation in healthy subjects and in type 2 diabetic patients: role of fat and carbohydrate meals. J Am Coll Cardiol 2002;39:1145-50.

8. Blackburn P, Després J-P, Lamarche B, Tremblay A, Bergeron J, Lemieux I, et al Postprandial variations of plasma inflammatory markers in abdominally obese men. Obesity 2006;14:1747-54

9. Unger RH. Minireview: weapons of lean body mass destruction: the role of ectopic lipids in the metabolic syndrome. Endocrinology 2003;144:5159-65.

10. Vogel RA, Corretti MC, Plotnick GD. Effect of a single high fat meal on endothelial function in healthy subjects. Am J Cardiol 1997;79:350-4

11. Cuevas AM, Germain AM. Diet and endothelial dysfunction. Biol Res 2004;37: 225-30.

12. Kim F, Pham M, Luttrell I, Bannerman DD, Tupper J, Thaler J, et al. Toll-like receptor-4 mediates vascular inflammation and insulin resistance in diet-induced obesity. Circ Res 2007;100:1589-96.

13. van Oostrom AJHHM, Sijmonsma TP, Verseyden C, Jansen EHJM, de Koning EJP, Rabelink TJ, et al. Postprandial recruitment of neutrophils may contribute to endothelial dysfunction. J Lipid Res 2003;44:576-83.

14. Simpson JL, Grissell TV, Douwes J, Scott RJ, Boyle MJ, Gibson PG. Innate immune activation in neutrophilic asthma and bronchiectasis. Thorax 2007;62 211-8.

15. Ordonez CL, Shaughnessy TE, Matthay MA, Fahy JV. Increased neutrophil numbers and IL-8 levels in airway secretions in acute severe asthma. Am J Respir Crit Care Med 2000;161:1185-90.

16. Jatakanon A, Uasuf C, Maziak W, Lim S, Chung KF, Barnes PJ. Neutrophilic inflammation in severe persistent asthma. Am J Respir Crit Care Med 1999;160: 1532-9.

17. Simpson JL, Scott RJ, Boyle MJ, Gibson PG. Inflammatory subtypes in asthma: assessment and identification using induced sputum. Respirology 2006;11 54-61.

18. Soutar A, Seaton A, Brown K. Bronchial reactivity and dietary antioxidants. Tho$\operatorname{rax}$ 1997;52:166-70

19. Strom K, Janzon L, Mattisson I, Rosberg H-E, Arborelius M. Asthma but notsmoking related airflow limitation is associated with a high fat diet in men: results from the population study "Men Born in 1914," Malmo, Sweden. Monaldi Arch Chest Dis 1996;51:16-21.

20. Bodner C, Godden D, Brown K, Little J, Ross S, Seaton A. Antioxidant intake and adult-onset wheeze: a case-control study. Eur Respir J 1999;13:22-30.

21. Weiland S, Von Mutius E, Husing A, Asther M. ISAAC Steering Committee: intake of trans fatty acids and prevalence of childhood asthma and allergies in Europe. Lancet 1999;353:2040-1.

22. Haby MM, Peat JK, Marks GB, Woolcock AJ, Leeder SR. Asthma in preschool children: prevalence and risk factors. Thorax 2001;56:589-95.

23. Nagel G, Linseisen J. Dietary intake of fatty acids, antioxidants and selected food groups and asthma in adults. Eur J Clin Nutr 2005;59:8-15.

24. Woods RK, Raven JM, Walters EH, Abramson MJ, Thien FC. Fatty acid levels and risk of asthma in young adults. Thorax 2004;59:105-10.

25. Wijga AH, Smit HA, Kerkhof M, de Jongste JC, Gerritsen J, Neijens HJ, et al. Association of consumption of products containing milk fat with reduced asthma risk in pre-school children: the PIAMA birth cohort study. Thorax 2003;58: 567-72.

26. Von Ehrenstein OS, Von Mutius E, Illi S, Baumann L, Bohm O, von Kries R. Reduced risk of hay fever and asthma among children of farmers. Clin Exp Allergy 2000;30:187-93

27. Tabak C, Wijga AH, de Meer G, Janssen NA, Brunekreef B, Smit HA. Diet and asthma in Dutch school children (ISAAC-2). Thorax 2006;61:1048-53.

28. Laerum BN, Wentzel-Larsen T, Gulsvik A, Omenaas E, Gislason T, Janson C, et al Relationship of fish and cod oil intake with adult asthma. Clin Exp Allergy 2007; 37:1616-23.

29. Juniper EF, O'Byrne PM, Guyatt GH, Ferrie PJ, King DR. Development and validation of a questionnaire to measure asthma control. Eur Respir J 1999;14 902-7.

30. GINA Executive and Science Committees. 2007 update: GINA report, global strategy for asthma management and prevention. Available at: http://www.ginasthma. org. Accessed August 10, 2008

31. Wood LG, H. P, Gibson PG. Mannitol challenge for assessment of airway responsiveness, airway inflammation and inflammatory phenotype in asthma. Clin Exp Allergy 2009;40:232-41. 
32. Wood LG, Fitzgerald DA, Lee AK, Garg ML. Improved antioxidant and fatty acid status following antioxidant supplementation is linked to improved lung function in cystic fibrosis. Am J Clin Nutr 2003;77:150-9.

33. Wood LG, Garg ML, Wood AJ, Gibson PG. A high fat challenge enhances innate immune responses in asthmatic airways. American Thoracic Society International Conference. New Orleans, USA, 2010:A2474.

34. Wood LG, Scott HA, Garg ML, Gibson PG. Innate immune mechanisms linking non-esterified fatty acids and respiratory disease. Prog Lipid Res 2009;48:27-43.

35. Zhao L, Kwon MJ, Huang S, Lee JY, Fukase K, Inohara N, et al. Differential modulation of Nods signaling pathways by fatty acids in human colonic epithelial HCT116 cells. J Biol Chem 2007;282:11618-28.

36. Rosenkranz SK, Townsend DK, Steffens SE, Harms CA. Effects of a high-fat meal on pulmonary function in healthy subjects. Eur J Appl Physiol 2010;109:499-506.

37. Beuther DA. Recent insight into obesity and asthma. Curr Opin Pulm Med 2010 16:64-70.

38. Chisty MN, Bellantone RA, Taft DR, Plakogiannis FM. In vitro evaluation of the release of albuterol sulfate from polymer gels: effect of fatty acids on drug transport across biological membranes. Drug Dev Ind Pharm 2002;28:1221-9.

39. Nappo F, Esposito K, Cioffi M, Giugliano G, Molinari AM, Paolisso G, et al. Postprandial endothelial activation in healthy subjects and in type 2 diabetic patients: role of fat and carbohydrate meals. J Am Coll Cardiol 2002;39:1145-50.

40. Alijada A, Mohanty P, Ghanim H, Abdo T, Tripathy D, Chaudhuri A, et al. Increase in intranuclear nuclear factor kappaB and decrease in inhibitor kappaB in mononuclear cells after a mixed meal: evidence for a proinflammatory effect. Am J Clin Nutr 2004;79:682-90.

41. Bellido C, López-Miranda J, Blanco-Colio LM, Pérez-Martínez P, Muriana FJ, Martín-Ventura JL, et al. Butter and walnuts, but not olive oil, elicit postprandial activation of nuclear transcription factor $\mathrm{\kappa B}$ in peripheral blood mononuclear cells from healthy men. Am J Clin Nutr 2004;80:1487-91.

42. Blum S, Aviram M, Ben-Amotz A, Levy Y. Effect of a Mediterranean meal on postprandial carotenoids, paraoxonase activity and C-reactive protein levels. Ann Nutr Metab 2006;50:20-4.

43. Lee JY, Sohn KH, Rhee SH, Hwang D. Saturated fatty acids, but not unsaturated fatty acids, induce the expression of cyclooxygenase- 2 mediated through Tolllike receptor 4. J Biol Chem 2001;276:16683-9.

44. Lee JY, Zhao L, Youn HS, Weatherill AR, Tapping R, Feng L, et al. Saturated fatty acid activates but polyunsaturated fatty acid inhibits Toll-like receptor 2 dimerized with Toll-like receptor 6 or 1. J Biol Chem 2004;279:16971-9.

45. Mozaffarian D, Aro A, Willett WC. Health effects of trans-fatty acids: experimental and observational evidence. Eur J Clin Nutr 2009;63:S5-21.

46. Wickens K, Barry D, Friezema A, Rhodius R, Bone N, Purdie G, et al. Fast foods are they a risk factor for asthma? Allergy 2005;60:1537-41.

47. Nagel G, Weinmayr G, Kleiner A, Garcia-Marcos L, Strachan DP. Effect of diet on asthma and allergic sensitisation in the International Study on Allergies and Asthma in Childhood (ISAAC) Phase Two. Thorax 2010;65: 516-22. 